\title{
Experiences of giving oseltamivir to school children during the 2009 influenza A(H1N1) pandemic
}

J Giesecke (johan.giesecke@ecdc.europa.eu)

1. European Centre for Disease Prevention and Control, Stockholm, Sweden

Citation style for this article:

Citation style for this article: Giesecke J. Experiences of giving oseltamivir to school children during the 2009 influenza A(H1N1) pandemic. Euro Surveill.

2010;15(19):pii=19570. Available online: http://www.eurosurveillance.org/ViewArticle.aspx?Articleld=19570

In this week's issue, Eurosurveillance publishes an article on experiences of giving oseltamivir to school children during the 2009 influenza $A\left(\mathrm{H}_{1} \mathrm{~N}_{1}\right)$ pandemic in the United Kingdom (UK) [1]. Already in 2009 the journal published two other studies on the same subject. $[2,3]$. All three studies were carried out in late spring 2009, when the UK still upheld its strategy of containment against the new influenza and together they report on a total of 638 children.

There are at least three reasons to give antivirals against influenza to children. The first is obviously to prevent or mitigate a disease that can be quite severe even in healthy children. The second is the mounting evidence that school children play a major role in the spread of an influenza epidemic $[4,5]$. The third is somewhat similar to the second, but rather a family than a society matter: to provide indirect protection for infant siblings that are too young to receive drugs or vaccine.

In the UK one year ago, the reason for offering oseltamivir to school children seems to have been a combination of the first two points mentioned above [6].

All three studies include rather young children, aged from 4 to 14 years. They were prompted by the laboratory confirmed diagnosis of one or more cases of 2009 pandemic influenza in the school and in addition each school was closed for at least one week. None of the studies had as a primary aim to assess the effectiveness of the intervention, but rather to measure frequency of adverse events and compliance with medication. Most of the children were given oseltamivir in prophylactic dosage, but those who matched the clinical criteria for influenza were given the drug as therapy.

The common finding from these studies is that the frequency of self-reported adverse events was considerably higher than previously reported for oseltamivir [7]. Around half the children in all the schools reported at least one symptom that could be associated with the drug. Nausea was most common, reported by almost one third of the children, followed by stomach pain in around one fifth. Other commonly reported symptoms $(>10 \%)$ were headache, sleeping problems and tiredness. One pupil and one adult staff reported mood changes that could have been of the type that has led to increased alertness [8].

Compliance varied across the studies: only $48 \%$ of the primary school children (aged 4-11 years) in one school finished the full course versus $85 \%$ of the slightly older children (aged 7-12 years) reported in this week's study. There was little difference in compliance between those children who reported influenza-like symptoms during the course and those who did not. The authors of this week's study performed a multivariate analysis of reasons for non-compliance and found that nausea, vomiting and rash were significantly associated with stopping the medication.

The studies presented add to our knowledge of the spectrum of adverse events when oseltamivir is used for treatment and/or prophylaxis in large groups of children. They indicate that expected benefits must be weighed carefully against side effects when this drug is considered for outbreak situations. In such situations, it may be worth to try to develop a simple instrument to decide who in the group would be at the highest risk of exposure and infection. One should also observe that even if antivirals are given to school children in order to diminish spread in society, the studies cited here indicate that this effect is limited - influenza is spreading also outside the school yards.

\section{References}

1. Strong M, Burrows J, Stedman E, Redgrave P. Adverse drug effects following oseltamivir mass treatment and prophylaxis in a school outbreak of 2009 pandemic influenza $A\left(\mathrm{H}_{1} \mathrm{~N}_{1}\right)$ in June 2009, Sheffield, United Kingdom. Euro Surveill. 2010;15(19). pii=19565. Available from: http://www. eurosurveillance.org/ViewArticle.aspx?Articleld=19565

2. Wallensten A, Oliver I, Lewis D, Harrison S. Compliance and side effects of prophylactic oseltamivir treatment in a school in South West England. Euro Surveill. 2009;14(30). pii=19285. Available from: http://www.eurosurveillance.org/ViewArticle. aspx?Articleld $=19285$ 
3. Kitching A, Roche A, Balasegaram S, Heathcock R, Maguire $\mathrm{H}$. Oseltamivir adherence and side effects among children in three London schools affected by influenza $A\left(\mathrm{H}_{1} \mathrm{~N}_{1}\right) \mathrm{v}$, May 2009 - an internet-based cross-sectional survey. Euro Surveill. 2009;14(30). pii=19287. Available from: http://www. eurosurveillance.org/ViewArticle.aspx?Articleld =19287

4. Reichert TA, Sugaya N, Fedson DS, Glezen WP, Simonsen L, Tashiro M. The Japanese Experience with Vaccinating Schoolchildren against Influenza. N Engl J Med.

2001;344(12):889-96.

5. Cauchemez S, Valleron AJ, Boëlle PY, Flahault A,

Ferguson NM. Estimating the impact of school closure on influenza transmission from sentinel data. Nature. 2008;452(7188):750-4.

6. Health Protection Agency. HPA advice on actions to be taken in a school in the event of a probable or confirmed case of "swine flu" being identified in a school pupil. HPA; 2009. [Available on request].

7. Roche Products Limited. Summary of product characteristics for Tamiflu. The electronic Medicines Compendium (eMC).

Hertfordshire: 2009. Available from: http://emc.medicines.org. uk/document.aspx?documentld=10446

8. US Food and Drug Administration (FDA). FDA MedWatch: 2008 Safety Alerts for Human Medical Products (Drugs, Biologics, Medical Devices, Special Nutritionals, and Cosmetics):

Tamiflu (oseltamivir phosphate) [3 April 2008]; Available from: http://www.fda.gov/Safety/MedWatch/Safetylnformation/ SafetyAlertsforHumanMedicalProducts/ucmo95044.htm 
